\title{
Coarse Aggregate Recycling by Pulsed Discharge Inside of Concrete
}

\author{
S. Inoue, J. Araki, T. Aoki, S. Maeda, S. Iizasa, M. Takaki, D. Wang, T. Namihira*, \\ M. Shigeishi, M. Ohtsu and H. Akiyama \\ Bioelectrics Research Center, Kumamoto University \\ 2-39-1 Kurokami, Kumamoto 860-8555, Japan
}

\begin{abstract}
In Japan, the treatment of waste concrete scraps has been one of the environmental issues. Therefore, new application using pulsed power discharge has been developed as the recycling method of the coarse aggregates from the waste concrete scraps. In the work, the dependences of the quality of the recycled coarse aggregate by the repetitive pulsed discharge treatments on the consumption energy were investigated. As the results, it was clear that the quality of the recycled coarse aggregate could be controlled by the number of discharge treatments. The recycled coarse aggregate, which satisfied class $\mathrm{H}$ under the regulations of Japan Industrial Standard (JIS A5005 and JIS A5021), was produced with the smallest consumption energy when the discharged energy from $0.02 \mu \mathrm{F}$ of capacitor charged up to $400 \mathrm{kV}$ applied to the waste concrete scraps during single discharge treatment.
\end{abstract}

PACS numbers: $52.80 . \mathrm{Wq}$

\section{Introduction}

In Japan, the most of waste concrete scraps have been reused as roadbed materials and the recycling ratio of waste concrete scraps has been kept over $98 \%$ from 2000 . However, it is expected that the demands of waste concrete scraps as roadbed materials would decrease even though the waste concrete scraps would increase with the pulling down buildings in next decade. It means that the recycling of waste concrete scraps would be in the unfavourable situation. In addition, amount of the natural aggregate deposit becomes smaller and it is recognized as one of the environmental issues. Therefore, the development of new recycling technology of waste concrete scraps is of paramount importance in Japan.

In the literature, the techniques of the destruction of solid material [1] and the drilling of wells [2] based on pulsed discharge were introduced. In the work, the pulsed power discharges inside of waste concrete scraps immersed in water were used to break the waste concrete scraps and to recycle the aggregates from it [3]. The discharge treatment of concrete has two features for recycling aggregate. One of them is that the discharge propagates in cement paste area in concrete and makes cement paste fragile. The other is that the shockwave due to heat expansion of the discharge makes tensile stress at boundary between cement paste and coarse aggregate and then the tensile stress separates cement paste from coarse aggregate. In the study, four discharge conditions were utilized to the discharge treatment of concrete scraps and then the best discharge condition was found.

\footnotetext{
* corresponding author; e-mail: namihira@cs.kumamoto-u.ac.jp
}

\section{Discharge treatment system for recycling aggregate}

\subsection{Pulsed power source}

Figure 1 shows the schematic diagram of the Marx generator used as pulsed power source in the work. The Marx generator consists of 5-10 stages of capacitor and

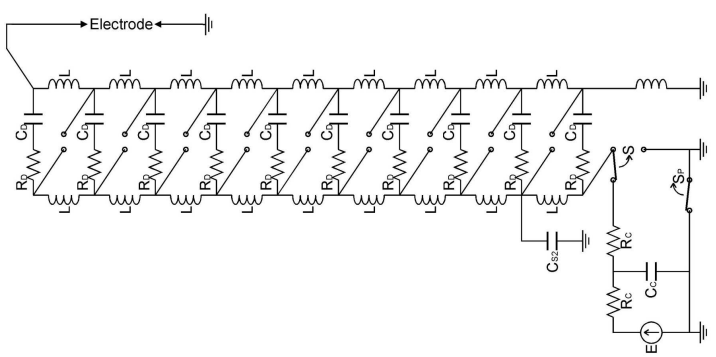

Fig. 1. Schematic diagram of Marx generator used in this work.

all capacitors were charged up to $-40 \mathrm{kV}$ in the operation. The $E, R_{C}, C_{C}, S_{P}, S, R_{D}, C_{D}, L$ and $C_{S 2}$ in Fig. 1 are with the dc power supply, the charging resistor $R_{C}(200 \Omega)$, the capacitor $C_{C}$ for the reduction of the reverse voltage to $E(0.2 \mu \mathrm{F})$, the mechanical $S$ switch for the protection of $E$, the mechanical switch $S_{P}$ of triggering the Marx generator, the discharge resistor $R_{D}(0.5 \Omega)$, the stage capacitor $C_{D}$ of the Marx generator $(0.8$ or $0.2 \mu \mathrm{F})$, the inductor $L(100 \mu \mathrm{H})$ and the capacitor for stable gap switching $C_{S 2}(1 \mathrm{nF})$. For the protection of the charging circuit including $E, R_{C}$ and $C_{C}$, it was separated from the Marx generator by simultaneous switching between $S_{P}$ and $S$ during the operation. Figure 2 indicates the typical waveforms of the applied 


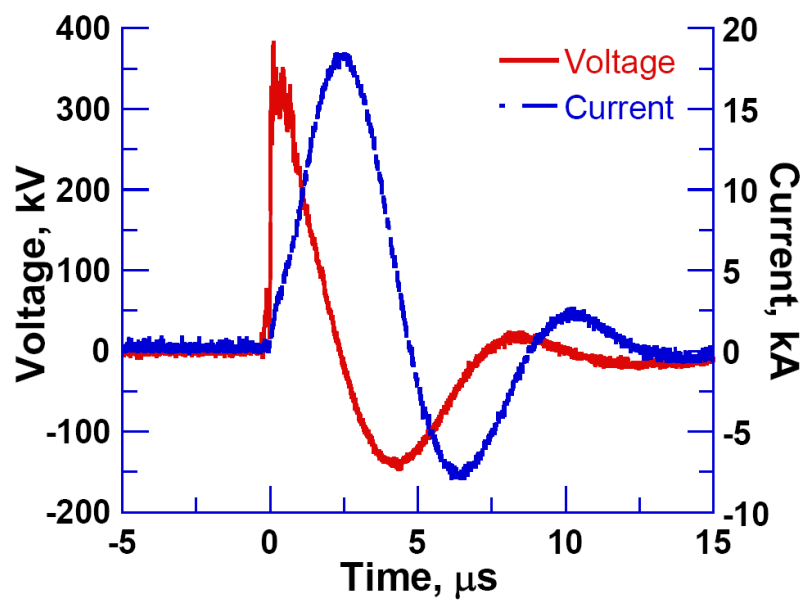

Fig. 2. Typical waveforms of output voltage and discharge current from Marx generator.

voltage and the discharge current into the concrete scrap in the experiment. The rise time of the applied voltage was less than $50 \mathrm{~ns}$. The peaks of the voltage and current reached up to $400 \mathrm{kV}$ and $20 \mathrm{kA}$, respectively.

\subsection{Experimental procedures}

Figure 3 shows schematic diagram of the discharge chamber when the test piece of concrete was put between the point and the hemisphere sieve electrodes immersed in water. The test piece of concrete had $150 \mathrm{~mm}$ width,

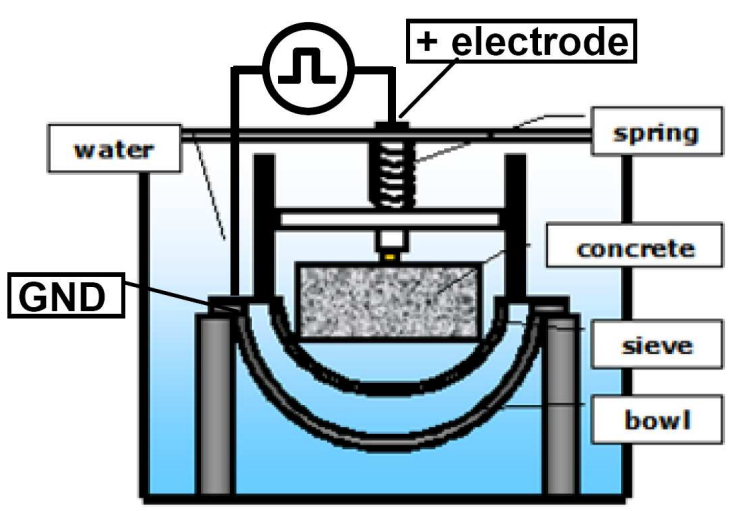

Fig. 3. Discharge electrode for concrete treatment.

$150 \mathrm{~mm}$ depth and $75 \mathrm{~mm}$ height. During the discharge treatment of the concrete, the positive pulsed voltage was applied to point electrode repetitively and the hemisphere sieve electrode was grounded. Figure 4 shows the progress of the repetitive discharge treatment of the test piece of concrete. In this time, the Marx generator had four discharge parameters, shown in Table, for the discharge treatment of the test piece of concrete. After the repetitive discharge treatments, the recycled aggregates, which were on the sieve electrode, were tested under the JIS regulation and then the density in oven-dry condi-
TABLE

Discharge parameters in experiments.

\begin{tabular}{l|c|c|c|c}
\hline \hline No. & 1 & 2 & 3 & 4 \\
\hline stage capacitor $[\mu \mathrm{F}]$ & 0.2 & 0.2 & 0.8 & 0.8 \\
stage number, stage & 5 & 10 & 5 & 10 \\
charging voltage $[\mathrm{kV}]$ & -40 & -40 & -40 & -40 \\
output voltage $[\mathrm{kV}]$ & 200 & 400 & 200 & 400 \\
discharge energy $[\mathrm{kJ}]$ & 0.8 & 1.6 & 3.2 & 6.4
\end{tabular}
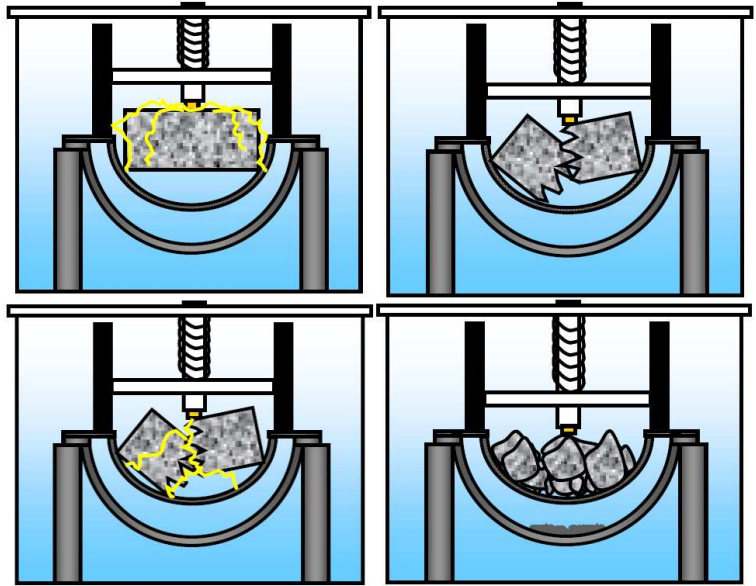

Fig. 4. Repetitive discharge treatment.

tion, the water absorption ratio and the fineness modulus of the recycled aggregates were obtained. Figure 5 shows the recycled aggregates after the repetitive discharge treatments in the case of using No. 4 discharge parameter in Table. From Figure 5, you can see that the quality of the recycled aggregate improved with the number of the discharge treatments.
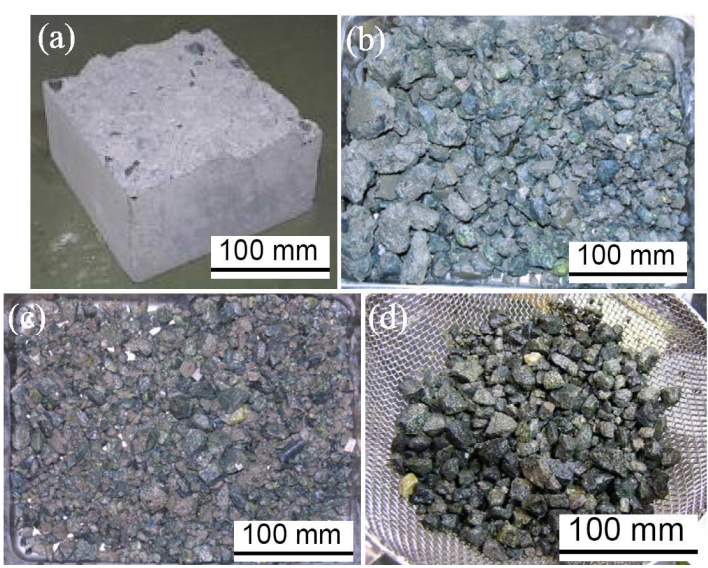

Fig. 5. Discharge treated aggregate: (a) Original.
(b) After 30 treatments.
(c) After 60 treatments.

(d) After 100 treatments. 


\section{Experimental results and discussion}

Figures $6 \mathrm{a}$ and $\mathrm{b}$ show the dependences of the qualities of the recycled coarse aggregate after discharge treatment

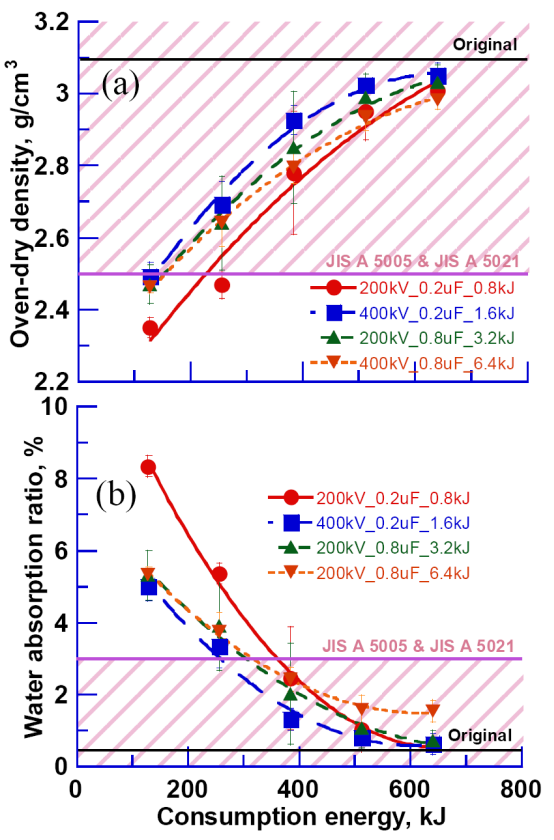

Fig. 6. Dependence of aggregate qualities on consumption energy.

on the consumption of energy. The consumption energy was calculated from the discharge energy during single discharge application and the number of the discharge applications. It is seems in Figs. 6a and b that the density in oven-dry condition and the water absorption ratio of the recycled coarse aggregate improved with increasing consumption energy. For the $1.6 \mathrm{~kJ}$ of the discharge condition (No. 2 in Table), the recycled coarse aggregates satisfied both the density in oven-dry condition and the water absorption ratio regulated by the Japan Industrial Standard (JIS A5005 and JIS A 5021, 4, 5) at the consumption energy of $250 \mathrm{~kJ}$. It is the smallest consumption energy among all discharge conditions. From the result, it is clear that the $400 \mathrm{kV}$ of the applied voltage is necessary to the efficient discharge treatment of the concrete.

\section{Summary}

In the work, the discharge treatment has been attempted as newly recycling way of the coarse aggregate from the concrete scraps. As a result, the following was deduced:

1. The discharge treatment of the waste concrete scraps could reproduce the aggregate with higher energy efficiency.

2. The optimum condition of the discharge parameters for the coarse aggregate recycling is the discharge energy of $1.6 \mathrm{~kJ}$ from $0.02 \mu \mathrm{F}$ of capacitor charged up to $400 \mathrm{kV}$.

\section{References}

[1] H. Bluhm, W. Frey, H. Giese, P. Hoppe, C. Schultheiss, R. Strassner, IEEE Trans. Diel. and Electr. Ins. 7, 625 (2000).

[2] I.V. Timoshkin, J.W. Mackersie, S.J. Macgregor, IEEE Trans. Plasma Sci. 32, 2055 (2004).

[3] T. Namihira, S. Narahara, S. Inoue, S. Maruyama, S. Iizasa, S. Maeda, Y. Tomoda, M. Shigeishi, M. Ohtsu, H. Akiyama, Proc. of Asia-Pacific Int. Symp. on the Basics and Applications of Plasma Technology, Kaohsiung, Taiwan, R.O.C., 50 (2007).

[4] JIS A 5005-1993, "Crushed stone and manufactured sand for concrete", 1993.

[5] JIS A 5021-2005, "Recycled aggregate for concrete-class H", 2005. 